\title{
THE HEALTH OF MALES IN NSW
}

\section{Marcello Gizzi}

Epidemiology and Surveillance Branch

NSW Department of Health

\section{Abdul Monaem \\ Men's Health Information and Resource Centre \\ University of Western Sydney, Richmond}

Gender is increasingly recognised as a significant determinant of health. Not only are there marked differences in measures of health between men and women, but also among men themselves. This article briefly describes the health of males in NSW as presented in readily available sources, in particular The Health of the People of NSWReport of the Chief Health Officer 2000 and the 1997-1998 NSW Health Survey Report. ${ }^{1,2}$

\section{OVERVIEW OF THE HEALTH OF MEN IN NSW}

In 1998, the estimated male population of New South Wales (NSW) was 3,146,345, which was slightly less than the female population. ${ }^{1}$ The life expectancy for males at birth in NSW in 1998 was 76.5 years compared with 81.9 year for women. ${ }^{1}$ However, life expectancy at birth for Aboriginal and Torres Strait Islander men in 1998 was 58 years, significantly lower than that of the non-indigenous men. ${ }^{1}$

Australian men have one of the highest life expectancies in the world. The World Health Report 2001 ranked their life expectancy fifth highest among all the member states and the rate was similar to the rate of the countries ranked above it. ${ }^{3}$ Life expectancy at birth for Australian men has increased steadily over the past 100 years, improving by 38 per cent. A man born in 1901 would anticipate living for 55.2 years. ${ }^{4}$

Utilising the Index of Relative Social Disadvantage, one of the Socioeconomic Indices for Area (SEIFA) developed by the Australian Bureau of Statistics, there is a strong social gradient of health within the NSW population. Over the period 1994-1998, for people aged 15-74 years, the most socioeconomically disadvantaged were more likely to die prematurely than those who were least disadvantaged. Further, the premature death rate from all causes was higher in males compared to females, along the social gradient. ${ }^{1}$

\section{PRINCIPAL CAUSES OF DEATH}

Approximately 44,900 NSW residents died in 1998, of which 23,570 were males. The leading causes of death for all men were cardiovascular diseases (37.8 per cent), cancers (29.4 per cent), respiratory diseases ( 9.9 per cent), and injury and poisoning (7.9 per cent). ${ }^{1} \mathrm{Men}$ in the $15-$ 64 year age group were nearly three times as likely to die from cardiovascular diseases than women of a similar age. ${ }^{1}$ Figure 1 shows the principle causes of death for males in NSW by age group.

Injury is the most common cause of death among young men in the 15-29 year age group. ${ }^{5,6}$ Road vehicle accidents and suicide account for approximately 80 per cent of injury related deaths in this age group. ${ }^{7,8}$ Indeed, suicide has replaced road vehicle accidents as the main cause of injury deaths since 1991 . Males accounted for 82 per cent of all suicides in NSW in $1998 .^{1}$

Lung and prostate cancer are the most common causes of cancer death among men. ${ }^{1}$ However, death rates from lung cancer have declined, while the death rates due to prostate cancer have changed little over the last 20 years. ${ }^{1}$

Geographical location and occupation also contribute to differences in death rates and health status among men. Of the 10,608 work related hospitalisations in NSW in 1999-2000, 85 per cent were for men. ${ }^{5}$ The most common sites of injury were the hand, back, and knees. ${ }^{5}$ There is a clear relationship between occupation and mortality: some occupations are more hazardous than others, and the geographical distribution of some occupations varies. For example, farmers suffer higher rates of injury and death than office workers.

\section{UTILISATION OF HEALTH SERVICES BY MEN}

Men tend to under-utilise the range of public and private health services available. Men are more likely to underreport symptoms of physical illness and delay seeking medical attention. An Australian report indicates that in comparison with women, men visit general practitioners and medical specialist offices less frequently, and spend less time in hospitals. ${ }^{9}$ The reasons cited for not accessing health services are many. These include time constraints, geographical distance, cultural differences, communication issues for non-English speaking men, and poor access to health services for Aboriginal males. ${ }^{10}$

As geographical remoteness increases so does the use by men of hospital emergency departments. Table 1 shows that among the area health services in NSW, Northern Sydney had the lowest emergency department attendances for males (9.4 per cent), and the highest number occurred in the Far West (30.2 per cent). ${ }^{2}$ Overall, emergency

\section{FIGURE 1}

PRINCIPAL CAUSES OF DEATH FOR MALES IN NSW BY AGE GROUP

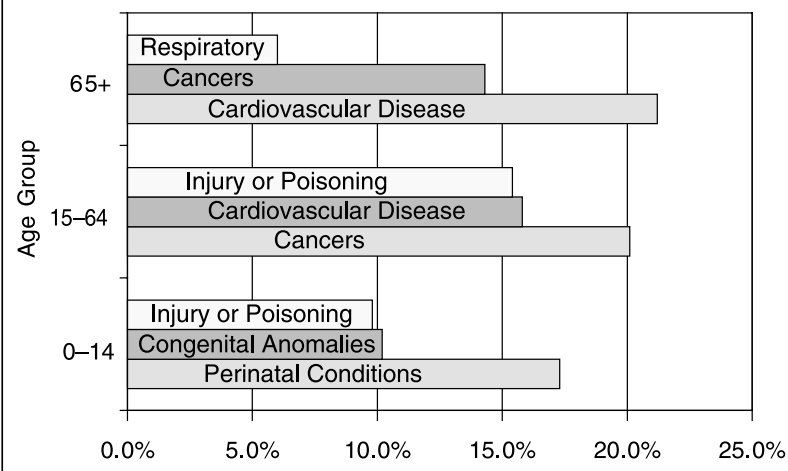

Source: The Health of the People of NSW-Report of the Chief Health Officer $2000 .^{1}$ 
department attendances by men in urban areas were much lower (13.0 per cent) than in rural areas (21.0 per cent $){ }^{2}$

The participation by men in health screening activities varies widely according to the risk factor considered. For instance, Figure 2 shows that in a 12-month period, 4.8 per cent of men had their blood pressure taken, 72.2 per cent had their blood cholesterol levels measured, and 40.3 per cent had a faecal test for bowel cancer. ${ }^{1}$

\section{RISK FACTORS IN MEN'S HEALTH}

Lifestyle factors contribute to the aetiology of the major causes of death including cardiovascular disease and cancer. In the 1997-1998 NSW Health Survey Report, 50 per cent of men reported being overweight and obese, ${ }^{2}$ while only 10.3 per cent reported eating the required levels of vegetables. However men have responded positively to many health messages, for example the percentage of men who are current smokers has declined to around 26 per cent in $1998,{ }^{2}$ from over forty percent in the $1980 \mathrm{~s} .{ }^{9}$ Also, 38 per cent of men reported in 1997-1998 that they applied sunscreen, ${ }^{2}$ and 67 per cent reported levels of adequate physical activity (Figure 3 ). ${ }^{2}$

The population health strategy outlined in this issue of the Bulletin involves linking 'lifestyle' factors with their socioeconomic context. The World Health Organization recognises unemployment as a social determinant of health, ${ }^{11}$ noting that evidence from a number of countries shows that, even allowing for other factors, unemployed people and their families suffer a substantially increased risk of premature death. ${ }^{11}$

Not only does unemployment cause lifestyle changes such as poor nutrition-which can lead to cardiovascular disease, respiratory disease, and hypertension - but also psychological wellbeing is affected. ${ }^{10-14}$ Low levels of psychological wellbeing can lead to depression and suicide. ${ }^{11-14}$ The effect of unemployment on physical and mental health problems tends to increase with the duration of unemployment. ${ }^{11-14}$

The unemployment rate among men in NSW has fluctuated considerably over recent years in line with economic conditions. For example in 1993 unemployment

\section{TABLE 1}

HEALTH SERVICES UTILISATION BY MEN: SELFREPORTED EMERGENCY DEPARTMENT ATTENDANCES, HOSPITAL ADMISSIONS, AND GENERAL PRACTITIONER VISITS IN A 12 MONTH PERIOD.

\begin{tabular}{|lccc|}
\hline $\begin{array}{l}\text { Area Health } \\
\text { Service }\end{array}$ & $\begin{array}{c}\text { ED } \\
\text { Attendances }\end{array}$ & $\begin{array}{c}\text { Hospital } \\
\text { Admissions }\end{array}$ & $\begin{array}{c}\text { General } \\
\text { Practitioner } \\
\text { Attendances } \\
\%\end{array}$ \\
\hline Central Sydney & 11.0 & 10.8 & 81.4 \\
Northern Sydney & 9.4 & 9.0 & 85.8 \\
South Eastern & & & \\
Sydney & 12.4 & 10.0 & 83.8 \\
South Western & & & \\
Sydney & 14.4 & 12.5 & 86.7 \\
Western Sydney & 11.2 & 9.5 & 83.2 \\
Wentworth & 14.3 & 11.3 & 86.2 \\
Central Coast & 15.2 & 14.8 & 89.7 \\
Hunter & 17.8 & 13.1 & 84.5 \\
Illawarra & 16.1 & 9.3 & 85.2 \\
Northern Rivers & 21.3 & 11.0 & 82.1 \\
Mid North Coast & 16.4 & 15.7 & 84.1 \\
New England & 21.8 & 13.2 & 78.2 \\
Macquarie & 22.3 & 13.5 & 79.0 \\
Far West & 30.2 & 13.9 & 78.6 \\
Mid Western & 24.7 & 14.4 & 82.0 \\
Greater Murray & 21.3 & 13.8 & 77.8 \\
Southern & 18.9 & 12.1 & 80.7 \\
All Urban & 13.0 & 10.8 & 84.9 \\
All Rural & 21.0 & 13.4 & 80.7 \\
NSW average & 14.8 & 11.4 & 83.9 \\
\hline Source: 1997-1998 & NSW Health Survey Report. ${ }^{2}$ & \\
\hline
\end{tabular}

was 13.3 per cent, while in 1999 it had fallen to 7.5 per cent. ${ }^{1}$ Unemployment rates for men are higher in rural areas. For 1996 the State average unemployment rate for men was 9.5 per cent, ${ }^{1}$ with the highest rate in the Mid North Coast Area Health Service (18.5 per cent), followed by the Northern Rivers Area (16.6 per cent). ${ }^{1}$

\section{CONCLUSION}

Men in NSW are living longer, and by international standards enjoy a high life expectancy. However, they

FIGURE 2

SCREENING MEASUREMENTS FOR THE NSW MALE POPULATION OVER A 12 MONTH PERIOD

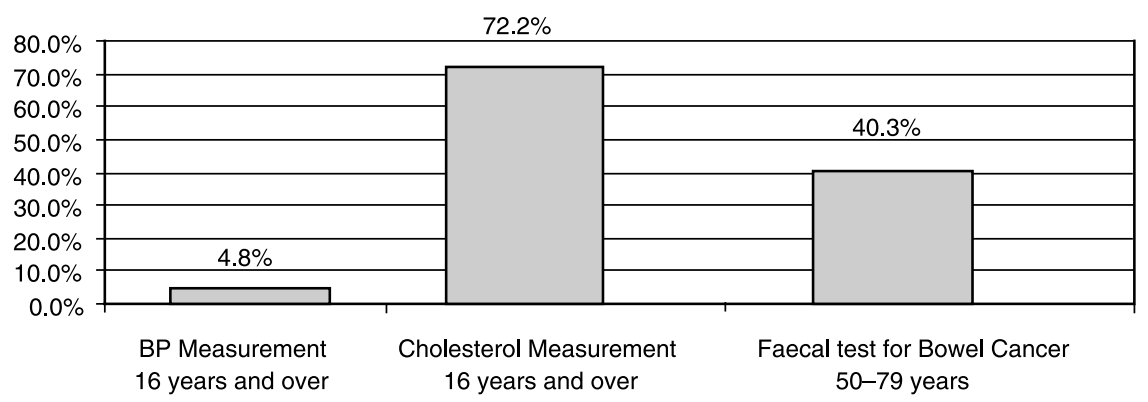

Source: 1997-1998 NSW Health Survey Report. ${ }^{2}$ 


\section{FIGURE 3}

\section{RISK FACTORS IN MALE HEALTH}

1

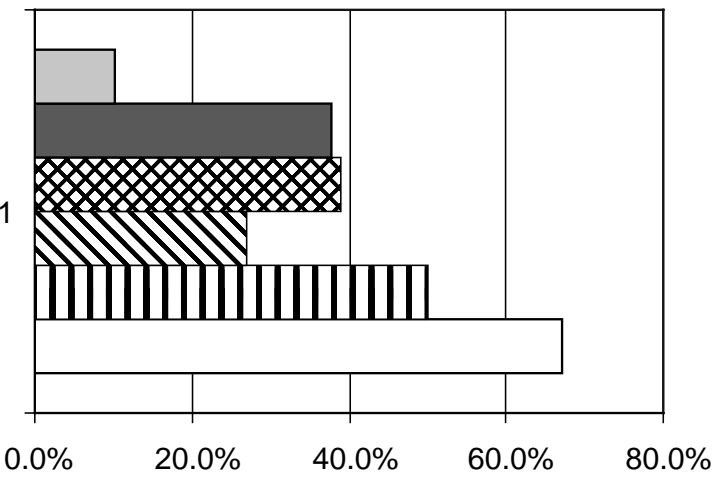

Key

$\square$ Eats required level of vegetables

$\square$ Eats Required level of fruits

$\square$ Application of sunscreen

$\Delta$ Smoking

I Overweight and obese

$\square$ Adequate physical activity

Source: 1997-1998 NSW Health Survey Report. ${ }^{2}$

tend to use health services at a lower rate than women, and die more frequently from cardiovascular disease, cancer, and injury including suicide. They also have poor health-related behaviours in health screening, nutrition, and smoking. Men also experience higher levels of hospitalisation due to work-related injuries.

As stated in Moving Forward in Men's Health, in order to promote and improve men's health, and make health services more appealling to men, further research is required into men's health, as well as a community-wide and intersectoral approach, so that all sectors of the community are working together.

\section{REFERENCES}

1. Public Health Division. The Health of the People of NSWReport of the Chief Health Officer 2000. Sydney: NSW Department of Health, 2000.

2. NSW Department of Health. 1997-1998 NSW Health Survey Report. www.health.nsw.gov.au.

3. World Health Organization. The World Health Report 2001Mental Health: New Understanding, New Hope. Geneva: World Health Organization, 2001.

4. AIHW. Australia's Health 2000. Canberra: AIHW, 2000.

5. Muscatello D, Mitchell R. Identifying Work-Related Injury and Disease in Routinely Collected NSW Hospitalisation Data. NSW Public Health Bulletin 2001; 12(7): 193-196.

6. Why Young Males. Australian Injury Prevention Bulletin. Issue $11,1995$.

7. Injury Patterns. Australian Injury Prevention Bulletin. Issue 11, 1995.

8. Ansari G, Chipps J, Stewart G. Suicide in New South Wales: The NSW Suicide Data Report. NSW Public Health Bulletin 2001; 12(3): 80-84.

9. AIHW. Australia's Health 1998. Canberra: AIHW, 1998.

10. Policy Division. Moving Forward in Men's Health. Sydney: NSW Department of Health, 1999.

11. Wilkinson RG and Marmot MG (editors). The Social Determinants of Health: the solid facts. Copenhagen: World Health Organization Centre for Urban Health, 1998.

12. Morrell SL, Taylor RJ, Kerr CB. Unemployment and Young People's Health. Med J Aust 1998; 168: 236-240.

13. Australian Bureau of Statistics. Year Book Australia - No. 83. Canberra: AusInfo, 2001.

14. Harris E, Harris M, Lee P, Powell Davies G. Taking Action to Address the Health Impact of Unemployment: Experiences from South Western Sydney. Sydney: CHETRE, 1999. 멸

\section{THE WELLBEING OF BOYS}

\section{Richard Fletcher}

Manager, Men and Boys Program,

Family Action Centre, University of Newcastle

This article describes the current health status of boys between $0-14$ years, and suggests ways that their wellbeing could be improved.

\section{HEALTH STATUS OF BOYS}

Boys in NSW have higher rates of death than girls in NSW for all major causes of childhood death (Figure 1). Boys also have higher rates of illness. For example, based on data presented in the Health of the People of NSW-Report of the Chief Health Officer 2000, ${ }^{1}$ boys have higher rates for hospital separations in NSW for respiratory diseases, perinatal conditions, and injury or poisoning. ${ }^{1}$ National health data shows that, when compared to girls, boys have higher rates of disability, handicap, and chronic and recent illness. ${ }^{2}$ Boys' wellbeing is also reflected in social indicators of health such as literacy levels, academic achievement and anti-social behaviour.

Nationally, for every socioeconomic group, boys perform worse than girls in assessments of literacy, and the gender gap is larger in the lower socioeconomic groups. ${ }^{3}$ Since 1975 , there is evidence of a decline in mastery of reading at age 14 among boys that is not evident among girls. ${ }^{4}$ When compared to girls, boys' achievement at university entrance level has also shown a recent decline in NSW, from 0.6 marks below girls in 1981 to 19.4 marks below girls in $1996 .{ }^{5}$ Eighty per cent of individuals suspended from school are boys, and boys are twice as likely as girls 